\title{
ACHIEVING GENDER EQUALITY IN TEACHING AND LEARNING: IDENTIFYING PROBLEMS AND SEARCHING FOR SOLUTIONS
}

\author{
GEORGE CRISTIAN BURSUC
}

\begin{abstract}
:
The paper intends to investigate the ways in which gender equality is perceived throughout the world, to identify the main concerns relating to gender equality and to pinpoint some international measures already taken in this field. The research for this paper is based on other studies, reports and analyses concerning gender equality conducted by several entities that have as their main interests the research of the gender variable in teaching. A local study was also conducted, where I tried to observe whether Romanian textbooks of English are sensitive to gender equality in their visual aids ("cotext"). Seven textbooks were analyzed, printed from 1997 to 2004, ranging from the $2^{\text {nd }}$ to $11^{\text {th }}$ grades. Both the theoretical and the practical aspects of the research reveal that although awareness concerning gender equality has been raised, gender equality is yet to be achieved. Neither the pragmatic aspects of teaching nor the written support represented by English textbooks treat boys and girls equally, thus reinforcing genderbased stereotypes and attitudes.
\end{abstract}

Keywords: gender, gender equality, gendered stereotypes, discrimination, equity, gender attitudes.

\section{Introduction}

An equitable education system prepares girls and boys equally to be productive and empowered citizens. Once in school, their education must be free of genderbased stereotypes, bias, and discrimination. However, ensuring gender equity within schools is a challenge for policy makers, curriculum planners and teachers throughout the world. In many countries education systems provide examples of curricula and teaching materials that reinforce stereotypes, of teachers with biased expectations and other different means that contribute to gender inequity promoted through the teaching and the learning processes. 


\section{A global view: girls}

In the case of girls, governments and donor agencies have focused primarily on increasing access and enrollment, with little or no attention paid to the quality or relevance of education for girls and or their retention and achievement rates. Primary school enrollment and completion rates are high, but the quality of education is low; thus, education does not confer the skills and knowledge for greater earnings, better health, and a more engaged citizenship. Not only access, but also duration and quality are critical variables in realizing educational benefits. Most efforts are focused on closing the primary school enrollment gap between boys and girls, with insufficient attention to gender dynamics that affect children's larger participation in school. Gender and educational inputs (curricula, textbooks, pedagogy, and teacher training) are rarely associated explicitly. Similarly, the strong connections between gender inequities, inputs and outcomes are not acknowledged sufficiently. For instance, a report of a USAID project in Malawi stated the focus was on girl's enrollment and attendance, without taking into consideration the obstacles in the learning process, thus putting girls at a disadvantage. The studies also revealed that girls have been regularly referred to as "dull, second-rate students, incapable of answering questions" (USAID, 2008) and were assigned tasks such as sweeping the floor and arranging furniture, whereas boys were given high status tasks such as ringing the school bell and timekeeping. Although considered as unimportant for child education, all these actions can contribute to reinforcing the gender gap in schools.

\section{A global view: boys}

Boys and men, on the other hand, have not been sufficiently engaged in actions dealing with norms and attitudes that would exercise gender equality. However, the existing interventions addressing constraints that limit the girls' participation in education have been successful. In a USAID project in Ethiopia, the boys' awareness of the burdens girls face in their schooling has been raised. Consequently, boys began to help their female classmates with their homework and gave up considering them intellectually inadequate. In other parts of the world, the situation is reversed: in Botswana, Lesotho and Namibia, boys are often taken out of school or even denied school enrollment entirely because of their traditional responsibility of herding cattle. In Latin America and the Caribbean, boys have higher repetition rates and lower achievements than girls. Several studies have been undertaken to discover the reasons for these low results. A study conducted by UNICEF in 2003 showed that boys' underachievement is closely linked to notions of gender, power and traditional socialization (e.g. language and literature is regarded as being rather feminine 
than masculine). In Jamaica boys were constantly referred to as being lazy and inattentive, which resulted in low self-esteem and poor academic results. (MSI/EQUATE 2005).

Regional educational differences such as these suggest that femalebased projects and interventions addressing gender inequalities should be grounded in competent gender analysis, should promote gender awareness, bring about changes in this direction and eventually, transform the power dynamics between the sexes.

\section{Identifying gender-related issues in schools}

Identifying gender-related issues in schools is easily done using available data, such as data systems concerning subject choices and test results. However, the focus on new areas, such as analyzing variations between classes or peer observation of lessons is likely to render rich results. Observations are key opportunities to gather data regarding gendered behaviors and gendered participation patterns that are at the basis of differences in achievement. Another way to determine gendered issues in school is talking about the issues that are important to boys and girls, which will enable teachers to address gender equality by understanding what conditions the simple fact of being a boy or a girl creates for pupils in their classrooms. Gendered self-perceptions are bound to be central to learning behaviors and choices, and these two can either be improved or negatively enforced by school and subject cultures. Two reliable pupil consultation methods are questionnaires, largely used for great numbers of students and preferred for their capacity of lowering inhibitions, and also focus group interviews, better for smaller groups of participants, and which can render an in-depth view of the issues to be analyzed.

\section{A gender-based pedagogy}

Thinking about a gendered-based pedagogy is not a far-fetched idea. Certainly, there are differences in the pupils' learning preferences and there are also teaching strategies that may lead to classroom success for a range of learners. Therefore, teachers could begin exploring gendered preferences for subjects, particular activities or preferred learning style, but at the same time use the insights they gain to improve rigor and variety in lessons for all learners. When it comes to organizing learning, a common approach to gendered acquisition differences over the last decade has been that of organizing single sex groups. This has been done on the basis that teachers can more easily address the issues and learning preferences of boys and girls in gendered groupings, which was also thought as having the advantage of less distraction from the opposite sex. Although there is some evidence that pupils find this method more favorable to 
learning, such groupings may preserve stereotypes and reinforce areas of weakness. Although the strategy of single sex grouping is mostly used to deal with male underachievement, research revealed that it is in the boys' groups that teaching strategies are often adapted and improved, while the girls undertake the same flow of information and approaches, thus limiting their potential. It is important, therefore, that regrouping is not seen as an answer in itself and that such measures are carefully evaluated and benefits shared among all pupils.

Teachers, as leaders of the classroom, have a large amount of control with respect to classroom management, but along with this power comes the responsibility concerning gender awareness and gendered approaches in the classroom. In this direction, teacher-student interaction is the starting point of achieving gender equality. The type of interaction the teacher organizes will have a powerful stand in determining the level of student contributions in the classroom; that is why the teacher should set the tone of his interaction from the very beginning. By constantly moving around the classroom, the teacher can interact with all the groups. Making eye contact, inviting students to participate and paying attention while they are talking, along with the other non-verbal cues conveyed, the teacher will leave the impression that the students are respected and this will make them engage better in classroom activities.

Norms, such as raising the hand for answering questions, will make the environment equal for everybody, as boys tend to interrupt or shout out their ideas, whereas girls are less spontaneous and not as drastic when it comes to sharing their opinions. Interruptions would make students (especially women) choose not to speak and shift the balance in favor of boys. Establishing norms will decrease this disparity and will increase female contributions to the dialogue.

Organizing work groups in the context of gender awareness is tricky and demanding, as many times women volunteer or are pushed into having secretarial roles which do not give them experience with other tasks. However, in a framework of gender equality all students need to gain experience in all task roles. To enforce that, the teacher must assign rotating tasks in each group, change the group membership constantly, or develop other methods which can break such exclusionary hierarchies.

Avoiding stereotypes is an absolute must for teachers, who often forget that even praising affirmations such as "Women write such neat lab reports" amount to constructing stereotypes that later affect gender perception. Instead, teachers should regard individual performance, without considering gender, age, race etc.

Course materials are sometimes not balanced and tend to rely more heavily on masculine terms. This may reinforce the idea that women are not as important or valid contributors in the classroom. If the learning materials used 
ignore the issues of gender, the teacher has to compensate for the bias in his/her presentation of it.

\section{Gender representations in European textbooks}

Transmitting gendered messages is a process which is more often than not subtle and not always noticed; the means by which such messages are delivered - and which have a great impact on students - are numerous. Textbooks, for example, play a special role in all educational systems, as they are almost the only tools for transmitting the curriculum. This makes the presentation of gender particularly powerful and significant.

Based on textbook analysis conducted in Europe, it was discovered that school textbooks and teaching materials transmit very strong messages about what it means to be male or female. However, the presentations of gender are problematic in two ways; first, they promote rigid roles and create stereotypes and second, the nature of the roles presented women at a disadvantage. Although reviewed constantly along the years, textbooks still present men and women as having different stereotypical gender roles. Women are predominantly portrayed undertaking domestic activities, raising children, doing housework, cooking, cleaning. In some countries (Albania, Hungary) most textbooks do not portray women outside of their home environments. On the other hand, there are very few examples of men involved in domestic activities, which creates the feeling that domestic work, including children care, is presented as women's work and inappropriate for men. This creates the "double burden" work responsibility inside and outside of the home which is a limiting factor on women's career prospects. Surveys conducted in Romania and Poland (UNICEF 1999) showed that more than two thirds of those polled thought that the burden on women's home responsibilities accounted for their poor representation in higher-level positions. Such an excessive emphasis leads to an inaccurate picture of their contribution to the economic life and maintains the view that they are more dispensable employees and may eventually lead to a higher rate of women unemployment in the region.

\section{Stereotypes and careers}

The stereotypes of what makes appropriate gender roles affect later career choices for girls and boys. In most countries, textbooks display an artificially created collection of occupations regarded as suited for their gender. Even though both boys and girls may suffer if they consider that only certain occupations are appropriate for them, the impact is much more serious for girls, because they are usually associated with low-paid and low-prestige jobs. In Romania, primary school textbooks show women as "school teachers, villagers, 
fruit or flower sellers, while men are viewed as astronauts, policemen, physicians, actors, conductors, and masons...". In other words, girls are externally pointed toward easy and family-oriented responsibilities and boys are channeled toward technical and profitable careers that would enable them to support financially their family in the future. The problem with such representations is that students see very limited, stereotyped ideas about what it means to be a man or a woman. Such messages influence them and limit their aspirations and yearnings. Textbooks should therefore be reformed by changing representation standards, supported by guidelines for textbook authors and the criteria for textbook evaluation.

Educational equity demands not only non-discriminatory textbooks and school curricula, but also knowledge and skills that students need to overcome the barriers of gender inequality. These barriers, not yet fully surpassed, include discriminatory attitudes, the "double burden" of women (both housework and a regular job), reproductive health issues, the commercial sexual exploitation of women, and domestic violence.

An important part in equipping students with the abilities to recognize and challenge gender inequities in society plays the introduction of critical thinking skills into curricula. Additionally, new courses in human rights and civic education have been introduced. Innovative programs addressing gender issues such as "Empowering Education" are inclusive of different learning styles, encourage active learning, and help children to improve decision making and critical thinking skills. Furthermore, students learn how to become better at collaborating, improving their self-esteem, and being sensitive to questions of gender and diversity. There is an entire range of skills that, once taught in schools, would enable girls to overcome any disadvantages and help boys and girls to live equitably together. These could be life skills curricula, with the ultimate purpose of teaching them how to run their own lives, negotiate personal relationships, cope with the hazards of alcohol, drugs and sexual activities. Sex education, especially for women, is vital to improving their lives. However, this is often a taboo subject and the few attempts to introduce sex education in schools have been hindered by resistance from teachers and parents and by inadequate teacher training.

Teachers' attitudes towards students and their gender can also have a strong impact on both girls' and boys' academic performance and their own attitudes and values. Even when teachers consider that their treatment is fair, research indicates that they often interact differently and inequitably with their male and female students. In Tajikistan, for instance, teachers are stricter with girls: many actions are considered natural for boys and are not permitted to girls.

\footnotetext{
${ }^{1}$ Research conducted by the Romanian Society for Feminist Analysis, in International Helsinki Federation for Human Rights, 2000
} 
In Albania, a World Bank study highlighted parental concerns about the unequal treatment of teachers as a result of gender-based prejudices. One parent stated that "Some teachers communicate differently with boys and girls. It is due to the lack of communication that many boys skip classes or drop out of school". There is also proof that some teachers have stereotypes about the intelligence of boys and girls. The same World Bank report revealed a widely held prejudice that boys are more intelligent than girls and that girls' good results are only due to their hard work. A similar study (Association of Women with University Education) found that 20 percent of the teachers thought that girls and boys should follow separate educational programs. Choosing a career follows a similar pattern: in Romania, teachers see the future of their students differently, according to their gender. Generally, well-paid and prestigious jobs are thought as being appropriate for boys (broker, economist, computer specialist) and lowpaid and low prestige jobs are thought as being appropriate for girls (nurse, hairdresser, secretary, public servant, babysitter). Together, stereotypes and prejudiced gender attitudes among teachers have an adverse effect on all students' academic performance, attitudes and values.

The school environment is relevant for ensuring gender equity in the classroom from two perspectives. It affects both girls' and boys' learning achievements and also provides an example of the adult world of work. In Europe, most secondary school teachers are women, but trends differ from country to country. For example, female teachers constitute more than 90 percent of all primary school teachers in certain countries (Armenia, Belarus, Bulgaria, Georgia, Latvia, Lithuania, Russia, Slovakia, Slovenia and Ukraine) and between 75 and 90 percent of all primary school teachers in Azerbaijan, Czech Republic, Croatia, Estonia, Hungary, Poland, Romania and Uzbekistan. The proportion of female teachers in primary and secondary schools grew rapidly after the 1990s, especially in some European countries. A reason for that is the declining status of teaching as a profession and the decrease in teacher salaries. It resulted in women being assigned to the poorly paid educational profession and the male exodus from the classroom.

In Romania, public sector wages including those in education are a third lower than the average for the economy as a whole ${ }^{1}$. The withdrawal of men from the teaching profession means that schools are becoming more and more single sex teaching environments. There are only a few exceptions, where men occupy teaching positions at an equal and growing rate to women in Albania, Moldova, Macedonia and Tajikistan. In Tajikistan, female teachers constitute $60 \%$ of all primary school teachers and $47.5 \%$ of all secondary school teachers. However, an equal distribution of men and women in the educational system is not necessarily a display of gender equity, at least in the case of Tajikistan, since

\footnotetext{
${ }^{1}$ Ministry of Macroeconomics and Statistics \& State Department of Statistics, 2000, p. 61
} 
teaching is one of the few stable jobs available in the context of an increasingly unemployed and impoverished population.

\section{The Romanian textbooks of English and the gender equality dimension}

My contact with English textbooks, regardless of the country of origin, did not offer me the certainty that gender equity is an explicit objective from the curriculum point of view. The legal documents dealing with education approach the issue of equality in the teaching process, but without any direct references to gender equality. Officially, there are no measures taken to supervise the content and the teaching approaches from English textbooks. Following remotely other similar studies, I have decided to analyze the most subtle means of conveying gendered messages, but effective nonetheless: these are the visual aids and more specifically, all the images that display people. I have analyzed 7 Romanian textbooks of English, published from 1997 to 2004, and that address students from the $2^{\text {nd }}$ grade to the $11^{\text {th }}$. I have focused on 5 gender-based interests:

\section{Male vs. female representation ratio}

This initial procedure was meant to measure the sheer number of men and women that appear in these coursebooks, since one of the ways of fighting gender discrimination is to ensure a fairly equal amount of illustrations of men and women. Out of a total of 1,246 illustrated people, $444(35,63 \%)$ are women, while $802(64,36 \%)$ are men. From this standpoint alone, it seems that gender equality is yet to be achieved.

\section{Profession displayed for each gender}

Studying the profession illustrated for each gender started from the idea that textbooks tend to create and reinforce stereotypes in what concerns female and male career choice and expectations from this point of view. The results show that most often illustrated professions do reinforce stereotypes; professions such as technician, astronaut, detective, police officer, pirate, mayor, carpenter, are traditionally associated to men. Jobs that can be considered neutral, such as shop assistant and dancer are scarce and professions that are traditionally considered feminine but practiced by men are inexistent.

Furthermore, it is obvious that men feature mainly professions which are usually well-paid and imply a certain degree of leadership and power.

The professions associated with women confirm, too, general stereotypes. Besides the obvious smaller proportion of female illustrations, women do seem to have low-prestige jobs or occupations: housewife, hairdresser, cheerleader and shop assistant are only a few which validate this rule. High prestige jobs are fewer in number, but females who represent them are fairly many. The most frequently illustrated female professions are fashion model, housewife, actress, teacher and doctor. Out of these, 4 are considered high prestige, but they add up 32 percent of the whole female profession illustrations. 


\section{Age}

Concerning age, data show that overall, most men illustrated in the studied textbooks are middle aged (300 cases), while the most frequent age category for women has been that of girls, with 173 representations. This has implications for the gender dimension since middle aged people are usually active in society and independent, while girls are vulnerable and dependent on adults.

\section{Interaction type}

How genders interact, to what extent, and who initiates the interaction are the subject of my next research point. Same sex interaction represents $43.42 \%$ vs. $56.57 \%$ different sex situations. There are, however, very intriguing variations: for the different sex interactions, males have the advantage of being the initiators (45 men initiators vs. 41 female initiators); for same sex interactions, only in 21 situations female-female interactions are illustrated, while male-male interactions count up to 48 .

\section{Type of activities}

Activities refer to the situations in which men and women were illustrated and, more specifically, their actions in those contexts. During my analysis, I took into consideration (and used for comparison) the traditional male and female activities from real life. Here are some examples of female activities: cooking a meal, washing the dishes, attending a patient, reading a book etc., and a few examples of male activities: holding a bat, operating a patient, hunting for animals, driving cars, playing in a band etc. These activities are arguably traditionally gendered and their presence in English textbooks confirms the hypothesis of gender inequality in the illustrations. There are only a few activities attributed to one gender or another that do not fit the convention.

\section{Conclusions}

Since gender equality has been viewed as an issue in teaching for several decades now, both macro and micro measures have been implemented. Programs and studies such as the ones initiated by UNICEF and USAID have a great impact on the targeted global areas, and classroom-related actions such as unbiased gender attitudes and curriculum, avoidance of gendered stereotypes and neutral interaction patterns are successfully raising the students' attention regarding gender equality. However, in order for this trend to continue, there is the need of a lifelong development of social partnerships between organizations from civil society and the political world, along with gender-based teacher training programs which will eventually eliminate the issues of gender in education.

Approaching the issue of gender in academic settings is by all means a significant path towards ensuring a right, virtuous and discriminatory-free educational environment. It is necessary for the students to know the differences 
between males and females and, more importantly, how the best collaboration can take place. The international measures taken by USAID, UNICEF and other similar organizations towards achieving equitable teaching are the pillars that support the structure of a new educational system, much more stable and aware of its own role in society. Nevertheless, raising the question of gender equality only within formal education (in schools) is misleading and belated. The right timing for such an endeavor is early childhood, when newborns come into contact with the world (DfES, 2007). Everything from choosing the toys they play with to clothing and forms of address amounts to creating gender bias and discrimination. In other words, teachers take over a job that was already initiated by the parents, and the ideas inoculated in the first years of life may remain immutable.

All in all, gender equality is yet to be achieved. Global measures are indeed a good step towards treating women and men equally in schools. However, there is the fundamental need of pairing such measures with the textbooks used in the classroom, which, at least in Romania, do not treat the two genders fairly. I personally militate for clear steps taken towards this goal, which would consider all the aspects of teaching rather than mass gendered-based projects with a shallow rationale and with little or no substantial effects.

\section{Works cited}

Egbo B. Gender in Language Education.Ontario, 2006. Print

Henes, Robby. Creating Gender Equity in Your Teaching. Center for Women in Engineering, 1994. Print

International Labor Organization (ILO). ABC of women worker's nights and gender equality. Geneva, 2000. Print

Magno, Cathryn; Silova, Iveta; Wright, Susan and Demeny, Eniko. Open Minds: Opportunities for Gender Equity in Education. New York, 200. Print

Management Systems International (MSI/EQUATE). A gender analysis of the educational achievement of boys and girls in the Jamaican educational system. Washington D.C., 2005. Print

Paule, Michele. Achieving Gender Equality in Teaching and Learning. Oxford, 2008. Print

The Department for Education and Skills (DfES). Gender and Education: the Evidence on Pupils in England.Nottingham, 2007. Print

USAID, Education from a Gender Equality Perspective. Washington D.C., 2008. Print 